NOAA

National Marine

Fisheries Service
Fishery Bulletin

¿ established 1881 ๙
Spencer F. Baird

First U.S. Commissione of Fisheries and founder of Fishery Bulletin
Abstract-Fish species of the Middle Atlantic Bight (MAB) continental shelf are well known; however, species occupying hard-bottom habitats, particularly on the outer shelf, are poorly documented. Reef-like habitats are relatively uncommon on the MAB shelf; therefore, shipwrecks may represent a significant habitat resource. During fall 2012 and spring 2013, 9 sites (depths: 42-126 m) near Norfolk Canyon were surveyed by using remotely operated vehicles. One site consisted of sand bottom, one consisted of predominantly natural hard bottom, and 7 sites included 8 large shipwrecks. Of 38 fish taxa identified, 33 occurred on hard bottom and 25 occurred on soft substrata. Fourteen fish taxa occurred almost exclusively on hard bottom, and 6 species were observed only on soft bottom. The most abundant taxa, especially on reef habitat, were the chain dogfish (Scyliorhinus retifer), a scorpionfish (Scorpaena sp.), the yellowfin bass (Anthias nicholsi), the red barbier (Baldwinella vivanus), the black sea bass (Centropristis striata), unidentified anthiine serranids, and the deepbody boarfish (Antigonia capros). Depth, location, and season did not significantly influence fish assemblages. Fish assemblages on natural and artificial hard-bottom habitat were similar but significantly different from soft-bottom assemblages. Deep-reef fishes of the southern MAB may be constrained by zoogeography, depth, and inadequate habitat-limitations that could increase their vulnerability.

Manuscript submitted 13 February 2015. Manuscript accepted 21 October 2015. Fish. Bull. 114:45-57 (2016).

Online publication date: 10 November 2015. doi. 10.7755/FB.114.1.4

The views and opinions expressed or implied in this article are those of the author (or authors) and do not necessarily reflect the position of the National Marine Fisheries Service, NOAA.

\title{
Fish species associated with shipwreck and natural hard-bottom habitats from the middle to outer continental shelf of the Middle Atlantic Bight near Norfolk Canyon
}

\author{
Steve W. Ross ${ }^{1}$ \\ Mike Rhode ${ }^{1}$ \\ Stephen T. Viada ${ }^{2}$ \\ Rod Mather ${ }^{3}$ \\ Email address for contact author: rosss@uncw.edu \\ 1 Center for Marine Science \\ University of North Carolina at Wilmington \\ 5600 Marvin Moss Lane \\ Wilmington, North Carolina 28409 \\ 2 CSA Ocean Sciences Inc. \\ 8502 SW Kansas Avenue \\ Stuart, Florida 34997 \\ 3 Applied History Lab \\ Department of History \\ University of Rhode Island \\ 80 Upper College Road \\ Kingston, Rhode Island 02881
}

The fish fauna of the shelf and upper slope of the U.S. Middle Atlantic Bight (MAB) (from Cape Hatteras to Cape Cod) is considered cool temperate, although fish enter from colder and warmer regions to the north and south, respectively. The estuarine and shelf fishes are particularly well studied in this region (e.g., Grosslein and Azarovitz, 1982; Colvocoresses and Musick, 1984; Gabriel, 1992; Murdy et al., 1997; Able and Fahay, 1998), in large part, because of decades of standardized, fishery-independent trawl surveys. Although fish communities have been documented on the open shelf and upper slope, their presence on untrawlable habitats (i.e., canyon walls, rocky bottom, and shipwrecks) has not been well documented.

The shelf of the Middle Atlantic Bight has a lower percentage of exposed natural hard substrata than that of other areas in U.S. Atlantic waters (Steimle and Zetlin, 2000; SEAMAP-SA, 2001). Therefore, habitat may be limiting for fauna in the MAB that require hard substrata, and therefore introduced shipwrecks or other reef-like habitats probably represent significant habitat resources. Even so, there has been little assessment of the fishes associated with either natural or artificial hard-bottom habitats in the MAB (Eklund, 1988; Adams, 1993; Steimle and Zetlin, 2000). Although direct observation techniques are preferred for assessment of the fauna of rugged hard substrata (e.g., Caillet et al., 1999; Quattrini and Ross, 2006; Ross and Quattrini, 2007), these methods have not been widely applied on the MAB shelf. Three studies that involved nearshore surveys in the MAB used direct observation to document fishes on various bottom types, including hard bottom, at depths $\leq 55$ m (Auster et al., 1991; 


\section{Table 1}

Details from dives of remotely operated vehicles (ROVs) on the continental shelf of the Middle Atlantic Bight during 2012 (ROV Kraken II) and 2013 (ROV Jason II), which were conducted from the NOAA ship Nancy Foster and the NOAA ship Ronald H. Brown. For site names, W=shipwreck sites; SS=shallow, soft-substrata site; NHB=natural hard-bottom site. Total time and depth range are for times when the ROV was on the bottom. Daytime (D) $=0800-2000$ h EDT; nighttime (N)=2000$0800 \mathrm{~h}$ EDT. n/a=not available.

\begin{tabular}{|c|c|c|c|c|c|c|c|c|c|}
\hline Dive no. & $\begin{array}{c}\text { Site } \\
\text { name }\end{array}$ & Date & Time & $\begin{array}{l}\text { Total } \\
\text { time } \\
(\mathrm{min})\end{array}$ & $\begin{array}{l}\text { Start } \\
\text { latitude } \\
(\mathrm{N})\end{array}$ & $\begin{array}{c}\text { Start } \\
\text { longitude } \\
\text { (W) }\end{array}$ & $\begin{array}{l}\text { End } \\
\text { latitude } \\
(\mathrm{N})\end{array}$ & $\begin{array}{l}\text { End } \\
\text { longitude } \\
\text { (W) }\end{array}$ & $\begin{array}{l}\text { Depth } \\
\text { range } \\
(\mathrm{m})\end{array}$ \\
\hline ROV-2012-NF-21 & SS & 20-Sep-12 & $\mathrm{D}$ & 304 & $37^{\circ} 10.90^{\prime}$ & $74^{\circ} 56.24^{\prime}$ & $37^{\circ} 10.85^{\prime}$ & $74^{\circ} 56.26^{\prime}$ & $42-43$ \\
\hline ROV-2012-NF-22 & $\mathrm{W}-1$ & 22-Sep-12 & $\mathrm{D}$ & 622 & $37^{\circ} 09.40^{\prime}$ & $74^{\circ} 45.30^{\prime}$ & $\mathrm{n} / \mathrm{a}$ & $\mathrm{n} / \mathrm{a}$ & 81 \\
\hline ROV-2012-NF-23 & $\mathrm{W}-2$ & 23-Sep-12 & $\mathrm{D}$ & 612 & $37^{\circ} 09.40^{\prime}$ & $74^{\circ} 34.60^{\prime}$ & $37^{\circ} 09.20^{\prime}$ & $74^{\circ} 34.40^{\prime}$ & 113 \\
\hline ROV-2012-NF-24 & W-3 & 24-Sep-12 & $\mathrm{D}$ & 519 & $37^{\circ} 13.90^{\prime}$ & $74^{\circ} 33.00^{\prime}$ & $37^{\circ} 14.00^{\prime}$ & $74^{\circ} 33.00^{\prime}$ & $124-126$ \\
\hline ROV-2012-NF-26 & $\mathrm{W}-4$ & 26-Sep-12 & $\mathrm{D}$ & 223 & $37^{\circ} 11.50^{\prime}$ & $74^{\circ} 34.40^{\prime}$ & $37^{\circ} 11.50^{\prime}$ & $74^{\circ} 34.40^{\prime}$ & $100-106$ \\
\hline ROV-2012-NF-27 & W-5 & 26-Sep-12 & $\mathrm{D}$ & 363 & $37^{\circ} 16.90^{\prime}$ & $74^{\circ} 32.10^{\prime}$ & $37^{\circ} 17.20^{\prime}$ & $74^{\circ} 32.00^{\prime}$ & $118-119$ \\
\hline ROV-2012-NF-28 & NHB & 27-Sep-12 & $\mathrm{D}$ & 291 & $37^{\circ} 01.06^{\prime}$ & $74^{\circ} 39.26^{\prime}$ & $37^{\circ} 00.92^{\prime}$ & $74^{\circ} 39.64^{\prime}$ & $98-117$ \\
\hline ROV-2012-NF-29 & W-6 & 27-Sep-12 & $\mathrm{D}$ & 251 & $36^{\circ} 54.80^{\prime}$ & $74^{\circ} 42.40^{\prime}$ & $36^{\circ} 54.80^{\prime}$ & $74^{\circ} 42.40^{\prime}$ & $84-85$ \\
\hline ROV-2012-NF-30 & $\mathrm{W}-7$ & 28-Sep-12 & $\mathrm{D}$ & 174 & $37^{\circ} 11.90^{\prime}$ & $74^{\circ} 45.40^{\prime}$ & $37^{\circ} 11.90^{\prime}$ & $74^{\circ} 45.40^{\prime}$ & $68-69$ \\
\hline ROV-2013-RB-692 & $\mathrm{W}-4$ & 19-May-13 & $\mathrm{N}$ & 295 & $37^{\circ} 11.50^{\prime}$ & $74^{\circ} 34.50^{\prime}$ & $37^{\circ} 11.50^{\prime}$ & $74^{\circ} 34.40^{\prime}$ & $91-105$ \\
\hline ROV-2013-RB-693 & $\mathrm{W}-2$ & 20-May-13 & $\mathrm{D}$ & 894 & $37^{\circ} 09.40^{\prime}$ & $74^{\circ} 34.40^{\prime}$ & $37^{\circ} 09.40^{\prime}$ & $74^{\circ} 34.70^{\prime}$ & $90-116$ \\
\hline ROV-2013-RB-694 & W-3 & 21-May-13 & $\mathrm{D}$ & 861 & $37^{\circ} 13.90^{\prime}$ & $74^{\circ} 33.10^{\prime}$ & $37^{\circ} 14.00^{\prime}$ & $74^{\circ} 33.10^{\prime}$ & $101-126$ \\
\hline ROV-2013-RB-695 & W-5 & 22-May-13 & $\mathrm{D}$ & 504 & $37^{\circ} 16.80^{\prime}$ & $74^{\circ} 32.10^{\prime}$ & $37^{\circ} 17.00^{\prime}$ & $74^{\circ} 32.20^{\prime}$ & $106-121$ \\
\hline ROV-2013-RB-696 & $\mathrm{W}-2$ & 23-May-13 & $\mathrm{D}$ & 197 & $37^{\circ} 09.40^{\prime}$ & $74^{\circ} 34.50^{\prime}$ & $37^{\circ} 09.40^{\prime}$ & $74^{\circ} 34.60^{\prime}$ & 90-114 \\
\hline
\end{tabular}

Adams, 1993; Diaz et al., 2003). Similar assessments in deeper waters of the middle to outer shelf are lacking, aside from those obtained from submersible surveys directed toward tilefish (Lopholatilus chamaeleonticeps) at depths of 117-268 m (Grimes et al., 1986). In these studies, the physical structure of habitat was observed to be correlated with fish distribution patterns. Higher profile, more complex habitats generally supported greater fish species richness and higher abundance for some species. Bioengineering by tilefish and associated species in and near canyon heads also created complex habitats for other outer shelf fauna (Grimes et al., 1986).

Non-natural hard substrata (e.g., shipwrecks) aggregate fish and invertebrates. The effects of artificial reefs composed of shipwrecks and other structures (e.g., drilling platforms and fish attracting devices) are well known but their use as fish habitat is still being debated (Stephan and Lindquist, 1989; Grossman et al., 1997; Perkol-Finkel et al., 2006). It is unclear whether artificial reef structures actually increase populations of fish as opposed to simply concentrating them, and understanding the role of artificial reefs is increasingly important considering the decline of natural reefs worldwide (Perkil-Finkel et al., 2006). However, Arena et al. (2007) reported that vessel-reefs off southeastern Florida supported significantly higher fish species richness and abundance than at natural reefs and that different community structures and trophic patterns were observed for the 2 habitat types, and they suggested that vessel-reefs enhanced local fish populations. The extent to which artificial reefs mimic natural reef func- tions requires further study, and artificial reefs may only approach the functions of natural reefs if their physical structures are similar (Perkol-Finkel et al., 2006).

As part of a larger survey of submarine canyons and nearby features in the MAB, historically important shipwrecks, naturally occurring hard bottom, and sandy bottom areas on the outer continental shelf near Norfolk Canyon were surveyed with remote operated vehicles (ROVs) in 2012 and 2013. In this article, we document 1) species of overall fish communities on shelf-depth artificial (shipwrecks) substrata and natural hard substrata and nearby soft-bottom habitats, 2) relative abundance of fish species in those communities, and 3) behaviors and distributions of fishes on shipwreck and nonshipwreck open bottom for 2 seasons (fall in 2012 and spring in 2013). The degree to which fishes were associated with hard bottom and the degree to which such habitats supported unique communities were investigated.

\section{Materials and methods}

\section{Study area}

On the middle to outer continental shelf (depths of 42$126 \mathrm{~m}$ ) of the southern MAB, 9 locations in the vicinity of Norfolk Canyon were surveyed with ROVs (Table 1, Fig. 1). These study sites had been mapped with multibeam sonar in 2011. The shallowest location (site SS) was the only one entirely composed of flat, soft sediment 


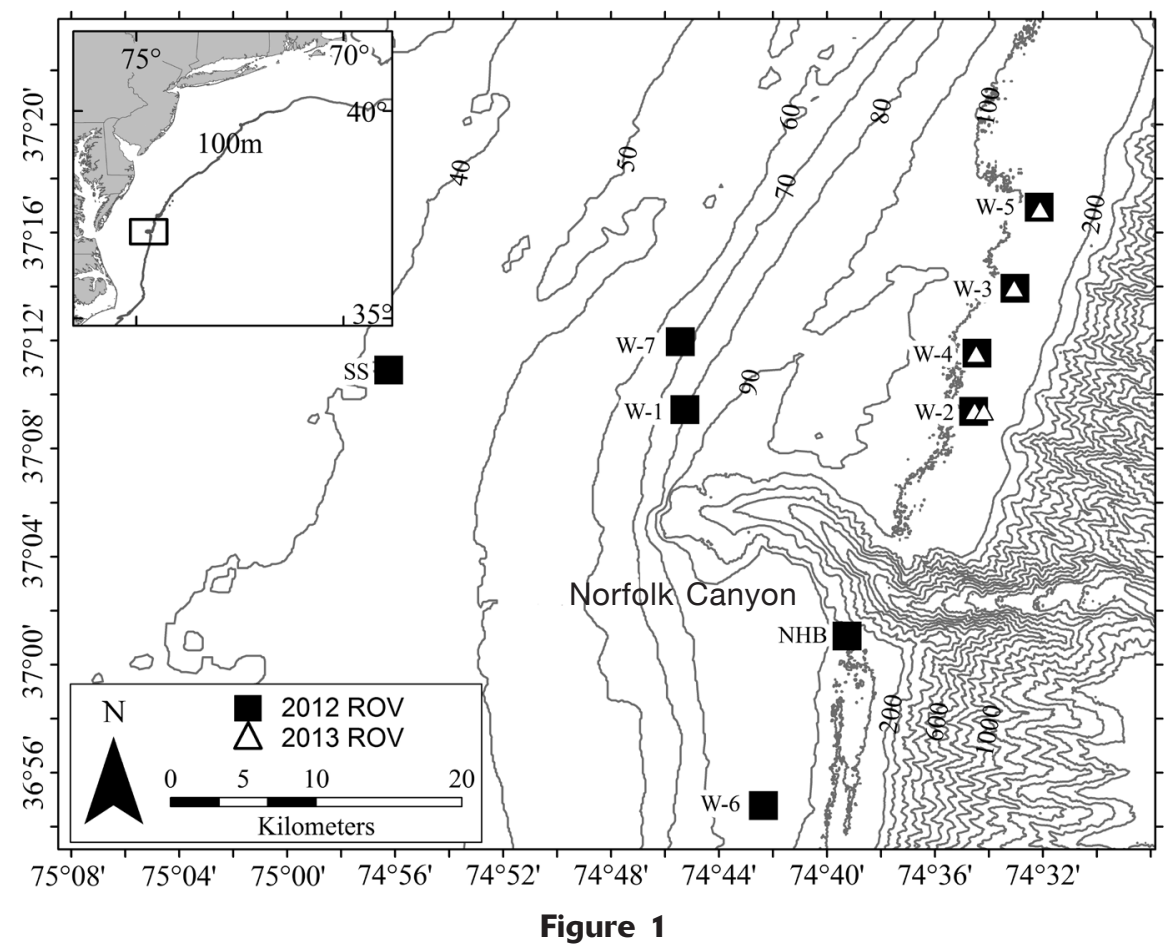

Locations of the 9 sites, 7 shipwreck sites (W-1 through W-7), 1 mostly natural hard-bottom (NHB) site, and 1 soft-bottom (SS) site, where remotely operated vehicles (ROVs) were used to collect data concerning fish assemblages on 20-28 September 2012 and 19-23 May 2013. Depth contours are given in meters. The inset illustrates the Middle Atlantic Bight; the rectangle indicates the study area.

bottom. All other sites comprised predominately hard, complex substrata, but they were also surrounded by soft substrata (see "Habitat definitions" section). The natural hard-bottom (NHB) location was dominated by hard, rough bottom, including boulders, rubble fields, and walls of consolidated mud. The dominant habitat in 7 of the study sites (e.g., W-1) was composed of 8 historically important shipwrecks, all sunk during the early 1920s (i.e., 6 of the ships were part of the "Billy Mitchell fleet" [Lee, 1949]). These shipwrecks had the following lengths and maximum heights off bottom: W-1 $(45 \times 6 \mathrm{~m}), \mathrm{W}-2(167 \times 18 \mathrm{~m}), \mathrm{W}-3(141 \times 7 \mathrm{~m}), \mathrm{W}-4$ $(301 \times 3 \mathrm{~m}), \mathrm{W}-5$ ( 2 shipwrecks about $685 \mathrm{~m}$ apart; $64 \times 3$ $\mathrm{m}$ and $53 \times 2 \mathrm{~m}), \mathrm{W}-6(171 \times 14 \mathrm{~m}), \mathrm{W}-7(72 \times 3 \mathrm{~m})$. The shipwrecks were surrounded by soft substrata (sand or gravel). All shipwrecks were covered to varying degrees with lost fishing gear (trawls, Fig. 2, A and C).

\section{Remotely operated vehicle}

Dives of the ROV were conducted with the University of Connecticut ROV Kraken II deployed from the NOAA Ship Nancy Foster on 20-28 September 2012 and, during a second research cruise, with the Woods Hole Oceanographic Institution ROV Jason II deployed from the NOAA Ship Ronald H. Brown on 19-23 May 2013. The site SS, the site NHB, and sites W-1, W-6, and W-7 each were sampled with 1 ROV dive, and each of the other shipwreck sites were sampled either 2 (W$3, \mathrm{~W}-4$, and $\mathrm{W}-5$ ) or 3 (W-2) times for a total of $14 \mathrm{ROV}$ dives (Table 1). The position of the ROV was recorded continuously by using an ultrashort baseline tracking system, and navigation data were time synchronized with all imagery and samples. An SBE 911plus ${ }^{1}$ conductivity, temperature, and depth (CTD) instrument (Sea-Bird Electronics Inc., Bellevue, WA) was attached to the ROVs to record conductivity (in microSiemens per centimeter), temperature (degrees Celsius), salinity, density ( $\sigma \theta$, in kilograms per cubic meter), dissolved oxygen (DO, in milliliters per liter), depth, and $\mathrm{pH}$ at a frequency of once per second during each dive. Only temperature, salinity, and DO data recorded during dives while the ROVs were on or near bottom are presented.

Digital video was collected as the ROVs moved along transects at slow speeds, $<\sim 25 \mathrm{~cm} / \mathrm{s}(<0.5 \mathrm{kt})$, across all habitat types and with the vehicles as near to bottom as possible. At each shipwreck, video and still image photo-mosaics were recorded over a series of parallel transects that covered the entire shipwreck. This digital imagery was used for vessel identification, examination of present ambient conditions and documentation

\footnotetext{
${ }^{1}$ Mention of trade names or commercial companies is for identification purposes only and does not imply endorsement by the National Marine Fisheries Service, NOAA.
} 

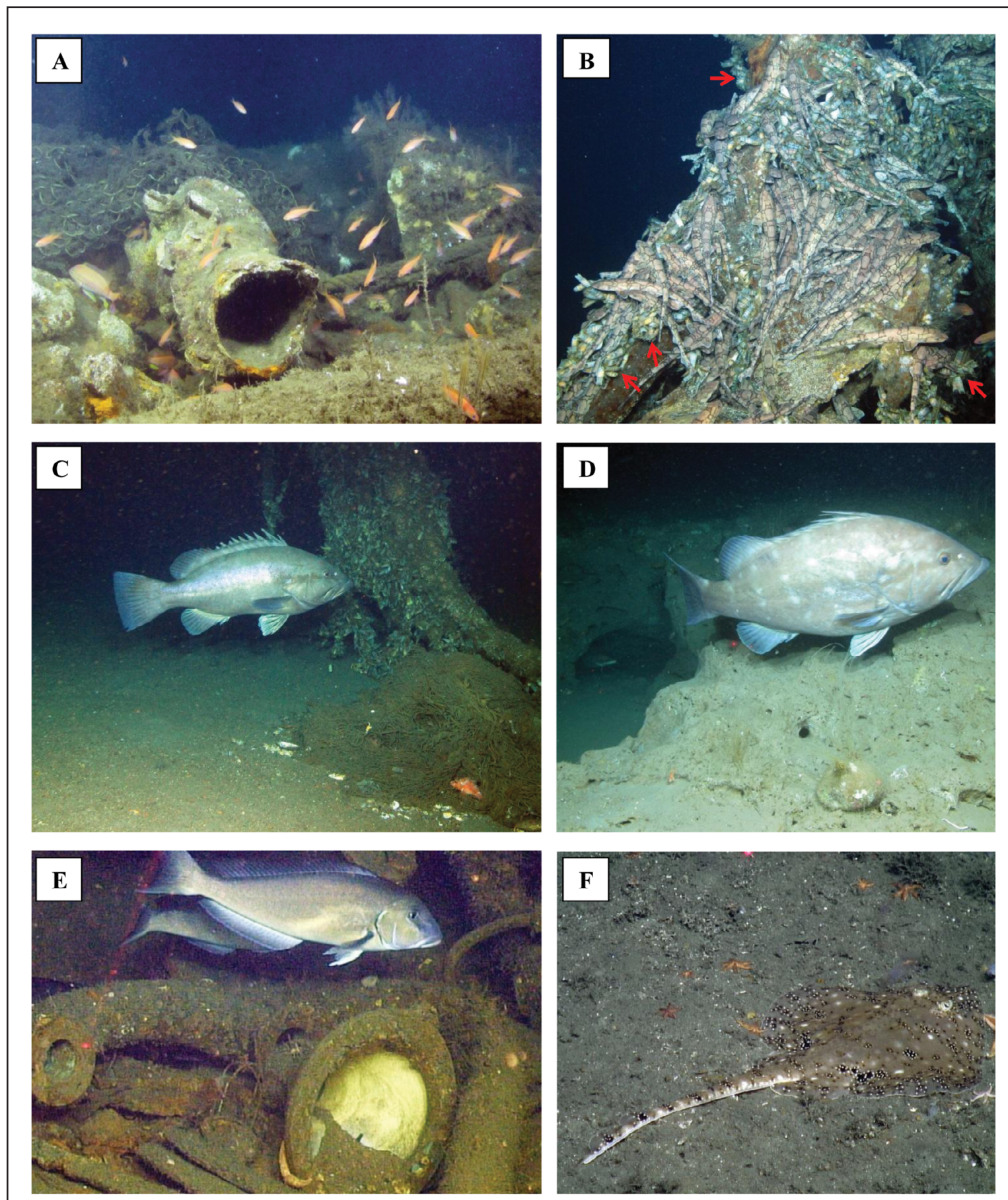

Figure 2

Photographs of fishes and habitats surveyed with remotely operated vehicles in 2012 and 2013 near Norfolk Canyon in the Middle Atlantic Bight: (A) school of unidentified anthiine serranids and at least one yellowtail bass (Anthias nicholsi, mid-left) on shipwreck site W-1, $81 \mathrm{~m}, 22$ September 2012; (B) dense aggregations of chain dogfish (Scyliorhinus retifer) lying on shipwreck structure (site W-5, 115 m, 26 September 2012), 4 yellowfin bass (2 upper right, 2 lower right), and red arrows indicate clusters of egg cases of chain dogfish; (C) warsaw grouper (Hyporthodus nigritus), and a scorpionfish (Scorpaena sp., lower right lying on trawl net) on shipwreck site W-5, 118 m, 26 September 2012; (D) snowy grouper (Hyporthodus niveatus) on the natural hard-bottom (NHB) site, $\sim 110 \mathrm{~m}, 27$ September 2013; the scaling laser dots near the anal fin indicate that this fish is at least $150 \mathrm{~cm}$ long in total length; (E) 2 blueline tilefish (Caulolatilus microps) on shipwreck site W-2, 100 m, 20 May 2013; and (F) rosette skate (Leucoraja garmaini) on sandy habitat near shipwreck site W-2, 100 m, 23 May 2013. 
of biota and habitats. The color video cameras attached to the ROVs had scaling lasers (10-cm spacing) used to estimate total length (TL) of fish. During transect surveys, the cameras were positioned to record directly in front of the ROV and were set on wide angle (or near wide angle). The video cameras recorded continuously throughout the ROV dives (whether the ROV was moving over transects or was stationary on bottom), and digital still images were taken frequently to augment video collection.

\section{Habitat definitions}

A main objective was to determine to what degree fishes were associated with general habitats on a large scale; therefore, habitat definition was reduced to 2 broad, relatively simple types: 1) soft substrata (SS) of sand or mud-relatively flat substrata and with few structuring features aside from gravel, burrows, depressions, and animal tracks; and 2) artificial (shipwreck) substrata and natural hard bottom (AS/NHB), which included World War I-era shipwrecks with substantial vertical profile and one site with natural hard bottom (consolidated mud, ledges, and boulders). Additional habitat metrics included bottom depth and environmental data recorded by the CTD instruments mounted on the ROVs.

\section{Video analysis: community and habitat association}

A preferred method for documenting fauna in complex habitats, visual observations (here based on ROV-collected video) were used to describe the fish communities and associated habitats at the 9 study sites. Tracks of ROV dives were processed initially to conservatively remove erroneous tracking data (location points) as described by Quattrini et al. (2012). To determine community structure and habitat associations of fishes at sites, much as described in Ross and Quattrini (2007), videos from each dive were viewed multiple times for habitat classifications (see "Habitat definitions" section) and for identification (to the lowest possible taxa) and enumeration of fishes by time of observation. Video segments were designated when the ROV stopped or started movement, when the video quality changed, or when the habitat changed. Depth was recorded by the ROV-mounted SBE 911plus for every time segment. Unusable video (out of focus, too far off bottom, because of malfunction, sediment clouds) was removed from the data set.

Species composition and relative abundances (fish counts) were determined from the wide-angle video and were compared within each of and between the 2 habitat types. To compare abundances of all species within a habitat type, relative abundances were calculated in percentages as the number of individuals per taxa per habitat type divided by the total number of individuals observed per habitat type and then multiplied by 100 . For comparisons between habitat type, analysis was restricted to benthic fishes identified to at least fam- ily level and with overall abundances $\geq 2$. Occurrence of at least 2 individuals allowed for the possibility of a taxa occurring in both habitat types. Relative abundances by habitat type were calculated for each taxon by dividing the number of individuals in a particular habitat type by the total number of individuals of the same species from both habitat types and multiplying the result by 100 .

Multivariate analyses were conducted in PRIMER 6 and PERMANOVA+ (PRIMER-E Ltd., Ivybridge, U.K.) (Clarke and Warwick, 2001; Clarke and Gorley, 2006; Anderson et al., 2008) to determine differences in benthic fish assemblages between habitat types. Sample units were the numbers of each species per habitat type (SS or AS/NHB) per ROV dive; samples with no species present were removed from the data set. Because transect times were variable, abundances of species were standardized per sample by dividing the number of individuals per species by the total number of fishes per sample. Standardized abundances were fourth-root transformed to down-weight the abundant species in relation to rare species. The Bray-Curtis similarity coefficient was used to calculate similarities between samples, and on the basis of the resulting similarity matrix a nonmetric multidimensional scaling ordination (MDS) plot and a dendrogram with group average linking were created. One-way analysis of similarities (ANOSIM) and post-hoc multiple comparison tests were used to determine whether there were significant differences between fish assemblages in the 2 different habitat types. Similarity percentage (SIMPER) analysis was used to determine which species contributed to the dissimilarities among habitat types.

\section{Results}

On the 9 study sites (depths of $42-126 \mathrm{~m}$ ), $14 \mathrm{ROV}$ dives were completed, 9 dives in September 2012 and 5 dives in May 2013 (Table 1, Fig. 1), resulting in $84.4 \mathrm{~h}$ of usable video data on hard-bottom (AS/NHB) habitat and $16.5 \mathrm{~h}$ of video data on soft-bottom (SS) habitat. Soft-bottom habitat was observed exclusively with video collected during the dive at the shallowest site (Table 1, Fig. 1); however, because only 3 specimens of unidentified skates were observed during this dive, it made little contribution to our study. Although shipwrecks and natural hard bottom were the focus of the remaining dives, soft-bottom habitat surrounding those hard-bottom habitats was also surveyed during these dives.

In September 2012, mean bottom temperatures varied about $2.5^{\circ} \mathrm{C}$ across the study sites; the coldest temperatures (means: $11.9-13.0^{\circ} \mathrm{C}$ ), lowest salinities (means: 33.1-34.8), and highest DO (means: 4.0-4.5 $\mathrm{mL} / \mathrm{L}$ ) occurred at the shallower sites (depths of 42-81 $\mathrm{m}$ ) (Table 2). At each of the 5 deeper sites (depths of 84-126 m), bottom temperatures (means: $14.2-14.5^{\circ} \mathrm{C}$ ), salinities (35.6-35.8), and DO (3.7-4.0 mL/L) were similar to each other. In May 2013, little variation was 


\section{Table 2}

Environmental data (means, ranges, and standard errors of the means in parentheses) recorded at bottom by the SBE 911plus system (one exception indicated at the footnote) attached to the remotely operated vehicles Kraken II (2012) and Jason II (2013) during surveys of shipwrecks and sandy bottoms on the continental shelf near Norfolk Canyon in the Middle Atlantic Bight. Site locations are appended to the dive year in each dive no. (see Table 1). NA=not available. DO=dissolved oxygen.

\begin{tabular}{lccc}
\hline Dive no. & Temperature $\left({ }^{\circ} \mathrm{C}\right)$ & Salinity & DO $(\mathrm{mL} / \mathrm{L})$ \\
\hline 2012-NF-21-SS & $12.16,11.95-12.29(0.0007)$ & $33.14,33.16-33.17(0.0001)$ & $4.51,4.45-4.55(0.0002)$ \\
2012-NF-22-W1 & $11.94,10.73-14.61(0.0029)$ & $34.16,32.92-34.94(0.0015)$ & $4.22,4.08-5.54(0.0005)$ \\
2012-NF-23-W2 & NA & NA & NA \\
2012-NF-24-W3 & $14.31,14.10-14.47(0.0003)$ & $35.65,35.32-35.80(0.0005)$ & $3.88,3.67-4.14(0.0003$ \\
2012-NF-26-W4 & $14.47,14.40-14.52(0.0001)$ & $35.78,35.69-35.80(0.0001)$ & $3.98,3.95-4.11(0.0001)$ \\
2012-NF-27-W5 & $14.15,14.00-14.46(0.0008)$ & $35.75,35.74-35.80(0.0000)$ & $3.69,3.51-4.84(0.0006)$ \\
2012-NF-28-NHB & $14.33,14.22-14.39(0.0002)$ & $35.71,35.50-35.77(0.0004)$ & $3.93,3.83-4.06(0.0004)$ \\
2012-NF-29-W6 & $14.21,13.86-14.30(0.0009)$ & $35.63,35.12-35.72(0.0013)$ & $3.84,3.67-4.85(0.0004)$ \\
2012-NF-30-W7 & $13.00,12.53-13.41(0.0013)$ & $34.76,34.45-35.09(0.0008)$ & $3.99,3.87-4.78(0.0004)$ \\
2013-RB-692-W4 & $13.16,13.09-13.32(0.0005)$ & $34.83,32.20-35.72(0.0085)$ & $2.99,1.81-4.22(0.0042)$ \\
2013-RB-693-W2 & $13.27,13.18-13.50(0.0003)$ & $32.81,29.66-33.14(0.0033)$ & $2.44,1.38-4.31(0.0018)$ \\
2013-RB-694-W3 & $13.42,12.90-13.49(0.0004)$ & $35.48,32.64-35.94(0.0027)$ & $3.08,2.09-4.46(0.0021)$ \\
2013-RB-695-W5 & $13.19,13.10-13.45(0.0004)$ & $29.42,26.38-35.18(0.0010)$ & NA ${ }^{1}$ \\
2013-RB-696-W2 & $13.32,13.00-13.60(0.0012)$ & $35.69,35.63-35.77(0.0002)$ & $4.71,4.57-4.76(0.0003)$ \\
\hline
\end{tabular}

${ }^{1}$ Data were taken from the Jason II conductivity, temperature, and depth (CTD) system, SBE 911plus, which was not operating.

again observed among the 5 deeper sites, but temperatures (means: $13.2-13.4^{\circ} \mathrm{C}$ ) were on average a degree colder than they were in 2012 . At these sites, more variations in salinity (means: 29.4-35.7) and DO (means: 2.4-4.7 $\mathrm{mL} / \mathrm{L}$ ) were recorded that those recorded in 2012. It seems unlikely that the small environmental variations were biologically significant to these temperate, wide-ranging fishes, particularly at the deeper sites, but monitoring over longer periods is required to determine the scale of environmental variation.

From analysis of the video from ROV dives, 38 unique fish taxa, representing at least 25 families, were identified (Urophycis sp., Hyporthodus sp., Anthiinae (unidentified), Caulolatilus sp., Labridae (unidentified), and unidentified fish not included in total counts; Table 3). Of those 38 taxa, 33 occurred on the AS/NHB habitat type (14 species were observed only on hard bottom), and 25 taxa occurred on the SS habitat type (6 occurred only on soft bottom) (Table 3 ). The lower number of species observed in the SS habitat type was at least partly due to lower dive effort there (Table 3). Three taxa, a requiem shark (Carcharhinus sp.), the greater amberjack (Seriola dumerili), and the ocean sunfish (Mola mola), that occurred over or near either habitat type are considered pelagic fish that are less constrained to benthic habitats.

Fish assemblages on each habitat type were numerically dominated by relatively few species. On the AS/ NHB substrata, $96.5 \%$ of the community was composed of 7 taxa (in decreasing order of abundance): unidentified anthiine serranids, the chain dogfish (Scyliorhi- nus retifer), the yellowfin bass (Anthias nicholsi), the deepbody boarfish (Antigonia capros), the red barbier (Baldwinella vivanus), a scorpionfish (Scorpaena sp.), and the black sea bass (Centropristis striata). Anthiine serranids (all combined, including yellowfin bass, red barbier, and unidentified members of this subfamily) and the chain dogfish (Fig. 2, A and B) were each an order of magnitude ( 2 orders of magnitude compared with most species) more abundant than any other taxa in either habitat type. Most of the Anthiinae fishes that were observed were probably red barbier, but small, rapidly moving anthiines can be difficult to identify in situ; some of these fishes could have been the streamer bass (B. aureorubens), longtail bass (Hemanthias leptus), or threadnose bass (Choranthias tenuis). The smaller ( 60-180 mm TL) fishes of the subfamily Anthiinae occurred as dense aggregations whose members swam rapidly around hard-bottom structures (Fig. 2 A), occasionally straying over nearby sandy bottom. Larger (usually 130-200 mm TL) yellowtail bass were more solitary and often associated with the anthiine schools (Fig. 2, A and B).

Six taxa (in decreasing order of abundance: the chain dogfish, the deepbody boarfish, the black sea bass, Scorpaena sp., the yellowfin bass, and anthiine serranids), accounted for $93.6 \%$ of the fauna on the SS habitat type but usually exhibited a lower percent contribution to the SS habitat type than to the AS/NHB habitat type (Table 3). Species that were unique to either habitat type occurred in low abundance $(<1 \%$ of total abundance within habitat). 


\section{Table 3}

Relative abundance (\%) of fishes observed during dives of remotely operated vehicles in 2012 and 2013 on 2 habitats types: 1) artificial (shipwreck) substrata and natural hard bottom (AS/NHB) and 2) soft substrata (SS) near Norfolk Canyon, Middle Atlantic Bight. Number of hours of observation (usable video) and depth ranges are provided under each habitat type.

\begin{tabular}{ccc}
\hline & AS/NHB & SS \\
Taxa & $84.42 \mathrm{~h}, 63-126 \mathrm{~m}$ & $16.48 \mathrm{~h}, 40-126 \mathrm{~m}$ \\
\hline
\end{tabular}

Scyliorhinidae

Scyliorhinus retifer, chain dogfish

30.158

56.489

Carcharhinidae

Carcharhinus sp., requiem shark

0.002

Rajidae

Leucoraja garmani, rosette skate

Rajidae (unidentified)

0.339

Ophichthidae

Ophichthus cruentifer, margined snake eel

Congridae

Conger oceanicus, conger eel

0.170

Gadiformes (unidentified), cods

0.002

0.085

Moridae

Physiculus fulvus, metallic codling

0.094

Phycidae

Phycis chesteri, longfin hake $\quad 0.002$

Urophycis chuss, red hake $\quad 0.002$

Urophycis regia, spotted hake $\quad 0.006$

Urophycis sp. 0.083

0.085

Lophiidae

$\begin{array}{ll}\text { Lophius americanus, goosefish } & 0.085\end{array}$

Trachichthyidae

Gephyroberyx darwinii, big roughy $\quad 0.600$

Macroramphosidae

$\begin{array}{lll}\text { Macroramphosus scolopax, longspined snipefish } & 0.557 & 0.254\end{array}$

Scorpaenidae

Scorpaena sp., scorpionfish $\quad 1.249$

6.107

Triglidae

Prionotus sp., searobin

0.085

Polyprionidae

Polyprion americanus, wreckfish $\quad 0.004$

Serranidae

Anthias nicholsi, yellowfin bass $\quad 10.667$

Anthias sp.

0.002

Baldwinella vivanus, red barbier

3.904

Centropristis striata, black sea bass

1.180

Hyporthodus nigritus, warsaw grouper

0.015

Hyporthodus niveatus, snowy grouper

0.058

Hyporthodus sp.

0.004

Pronotogrammus martinicensis, roughtongue bass

0.006

Anthiinae (unidentified)

44.606

1.442

Malacanthidae

Caulolatilus microps, blueline tilefish

0.369

0.594

Caulolatilus sp.

0.339

Pomatomidae

Pomatomus saltatrix, bluefish 0.137

1.781

Carangidae

$\begin{array}{lll}\text { Seriola dumerili, greater amberjack } & 0.062 & 0.085\end{array}$

Sparidae

Stenotomus chrysops, scup

0.009

0.509 


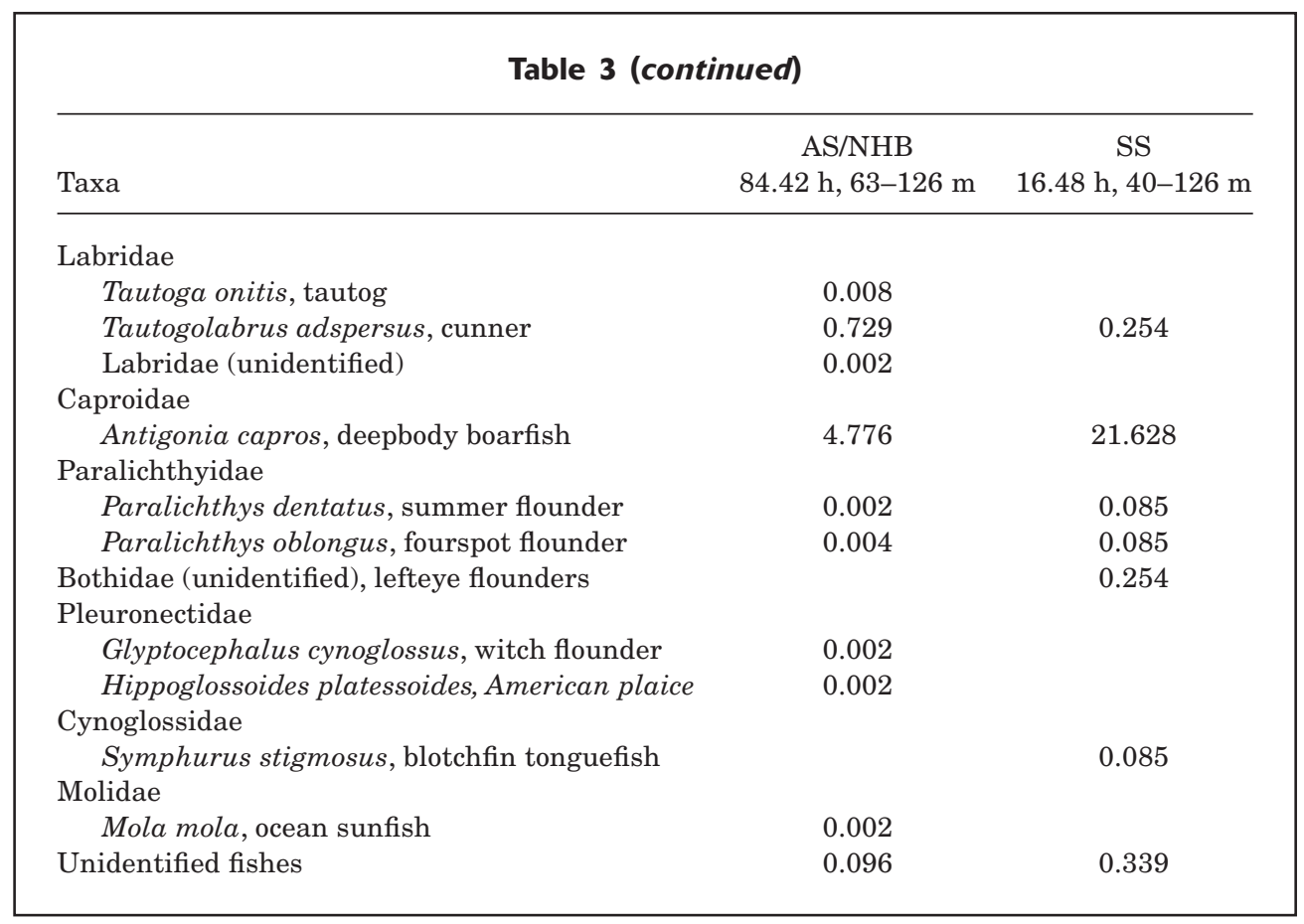

Chain dogfish were less abundant on the natural hard bottom (site NHB) than on the shipwreck (AS) or SS habitats. They occurred in massive numbers at the shipwreck sites, where they were often so densely packed that they lay on top of each other in layers that were several individuals thick (Fig. 2B). Individuals and aggregations of individuals were observed on all areas of the shipwreck sites, including on and within the trawl nets that covered sections of the shipwrecks. Although many chain dogfish were observed lying on soft bottom, they did so generally within tens of meters of the shipwrecks. The aggregations of chain dogfish probably reflect activity related to spawning because thousands of their egg cases were attached to the shipwreck structures and the nets that covered them (Fig. 2B).

Because shelf communities are subjected to seasonal environmental variability and may exhibit seasonal distribution patterns, multivariate analysis was used to examine seasonal differences (fall 2012 versus spring 2013) in fish distributions at the 4 study sites that were sampled during both seasons; 17 video samples ( 8 for fall, 9 for spring) and 29 species were examined in this analysis. Season did not have a significant impact on fish assemblages (ANOSIM, coefficient of multiple correlation $[R]=-0.024, P=0.55$ ). Likewise, there were no differences in assemblage structure over the limited depth range examined ( 8 sites, depths of 68-126 m, dive NF-21 at site SS excluded, $R=0.026$, $P=0.400$ ). The greatest distances between sites were no more than $50 \mathrm{~km}$, and fish assemblages (excluding observations from dive NF-21) at the 8 sites were not significantly different $(R=0.130, P=0.090)$ in regard to distance from one another or distance from Norfolk
Canyon. Therefore, all data were combined for analysis of habitat influence on fish assemblages.

Multivariate analysis of 26 video samples (excluding those from the shallow dive NF-21) and 41 taxa, indicated a significant difference $(R=0.499, P=0.001)$ in fish assemblage structure between the soft bottom (SS) and hard bottom (AS/NHB) habitat types (Fig. 3). The video samples from the AS/NHB habitat type were $60 \%$ dissimilar from the 2 sample groups affiliated with the SS habitat type; the video sample associated with natural hard-bottom habitat (at site NHB) grouped with the shipwreck hard-bottom (AS) samples (dive number 28, Fig. 3). The fishes most influencing the group of samples from the AS/NHB habitat type (on the basis of SIMPER analysis) were the chain dogfish, members of Anthiinae, the yellowfin bass, the deepbody boarfish, the conger eel (Conger oceanicus), Scorpaena sp., the red barbier, the cunner (Tautogolabrus adspersus), and the blueline tilefish (Caulolatilus microps). Fishes most influencing the groups of samples from the SS habitat type were the chain dogfish, Scorpaena sp., the deepbody boarfish, and the black sea bass.

Data indicates at least some difference in fish communities along isobaths. Within the hard bottom group, video samples $(n=9)$ from the 4 deeper shipwreck habitats (AS) north of Norfolk Canyon (depths of 91-126 m; Fig. 1) grouped closely together (Fig. 3), although data were collected in 2 different years and seasons. The 3 shipwreck hard-bottom (AS) video samples from the shallower middle shelf (depths of 68-85 m; Fig. 1) were offset together in the overall group of samples from the AS/NHB habitat type (dive numbers 22, 29, 30; Fig. 3). The 3 samples from sandy bottom on the middle shelf (SS habitat type, dive numbers 22, 29, 30; Fig. 3) also 
were set apart from most other SS samples (Fig. 3). Fishes that occurred in deeper waters $(>90 \mathrm{~m})$ that were missing from those 3 middle shelf sites, regardless of habitat type, were the metallic codling (Physiculus fulvus), the big roughy (Gephyroberyx darwinii), the longspine snipefish (Macroramphosus scolopax), groupers (Hyporthodus spp.), and the deepbody boarfish. Two species common on the middle shelf sites, the scup (Stenotomus chrysops) and the tautog (Tautoga onitis), were not observed on the deeper sites.

Habitat preference also was indicated by relative abundance patterns of most benthic fishes. The hard bottom (AS/NHB) habitat type contained $\geq 89 \%$ of the abundance of each of 22 fish taxa (i.e., the first 22 species in Fig. 4), and far more individuals were observed overall in that habitat type than in the SS habitat type. Several species, including a searobin (Prionotus sp.), the fourspot flounder (Paralichthys oblongus), the summer flounder ( $P$. dentatus), and the scup, used both soft- and hard-bottom habitats frequently. A few taxa, including lefteye flounders (Bothidae), the margined snake eel (Ophichthus cruentifer), and the rosette skate (Leucoraja garmani), were observed only on soft bottom (Figs. $2 \mathrm{~F}$ and 4 ).

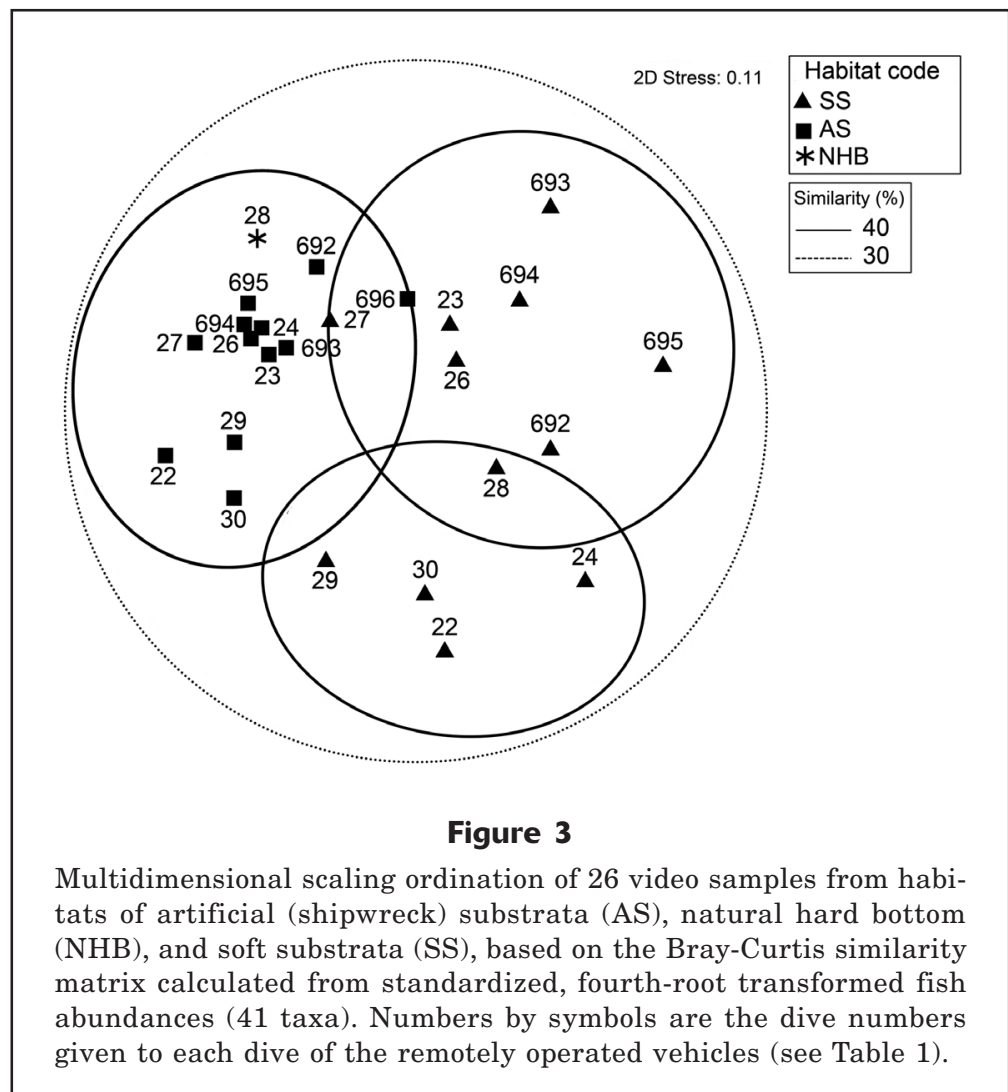

\section{Discussion}

Fishes that occupied natural and artificial hard-bottom habitats on the middle to outer shelf of the MAB exhibited an assemblage structure in our study that was different from that of the well-documented (e.g., Murawski et al., 1983; Mahon et al., 1998) ichthyofauna of MAB soft-bottom habitats. Although the most abundant reef (i.e., hard-bottom) species also were observed and counted on soft-bottom habitat, in most cases they were never far from reef structures. The hard-bottom habitats surveyed in our study were dominated by cooltemperate and warm-temperate species that are generally considered to be reef associates, although some (e.g., the chain dogfish, black sea bass, and conger eel) have broad depth and latitudinal distributions and large-scale habitat use. Other species common to the hard-bottom habitats (e.g., most Serranidae, the tautog, the blueline tilefish, and the deepbody boarfish) exhibited more restricted distributions and tighter association with reefs. Species of Serranidae (excluding the black sea bass) in particular seemed constrained to a relatively narrow depth range (from $\sim 70 \mathrm{~m}$ to at least $150 \mathrm{~m}$ ) in the MAB, most likely because of the generally warmer $\left(>10^{\circ} \mathrm{C}\right)$ and less variable bottom water temperatures along the outer shelf of the southern MAB (Colvocoresses and Musick, 1984).

In contrast to most of the fishes associated with soft-bottom habitats, several of the abundant hardbottom species (Fig. 2, A-E; e.g., the yellowfin bass, the red barbier, groupers, and the blueline tilefish) were further constrained by being at or near the northern limits of their adult ranges (Moore et al., 2003; Anderson and Heemstra, 2012). Because many of the common hard-bottom species (e.g., most of the Serranidae and the chain dogfish and deepbody boarfish) likely have an obligate association with reef-like habitats (Able and Flescher, 1991; Craig et al., 2011; Anderson and Heemstra, 2012), the relatively limited extent of hard bottom in the MAB (Steimle and Zetlin, 2000) would also affect their distribution. Therefore, an abundant component of the hard-bottom fish community in the southern MAB is restricted by habitat availability, depth, and zoogeography, of which the latter 2 constraints probably are related to bottom temperature. Although this reef community of the outer shelf appears to flourish, these limitations likely make it vulnerable to overfishing, habitat damage, and large-scale environmental variations.

Results presented here differ substantially from those of other surveys of the MAB. Our ROV study sites overlapped with some of the areas of fish groupings that were based on decades of bottom trawl surveys (Colvocoresses and Musick, 1984; Mahon et al., 1998); however, the majority of species common to this study and these 2 trawl-based studies were species that are reported to be most common on sandy bottoms 


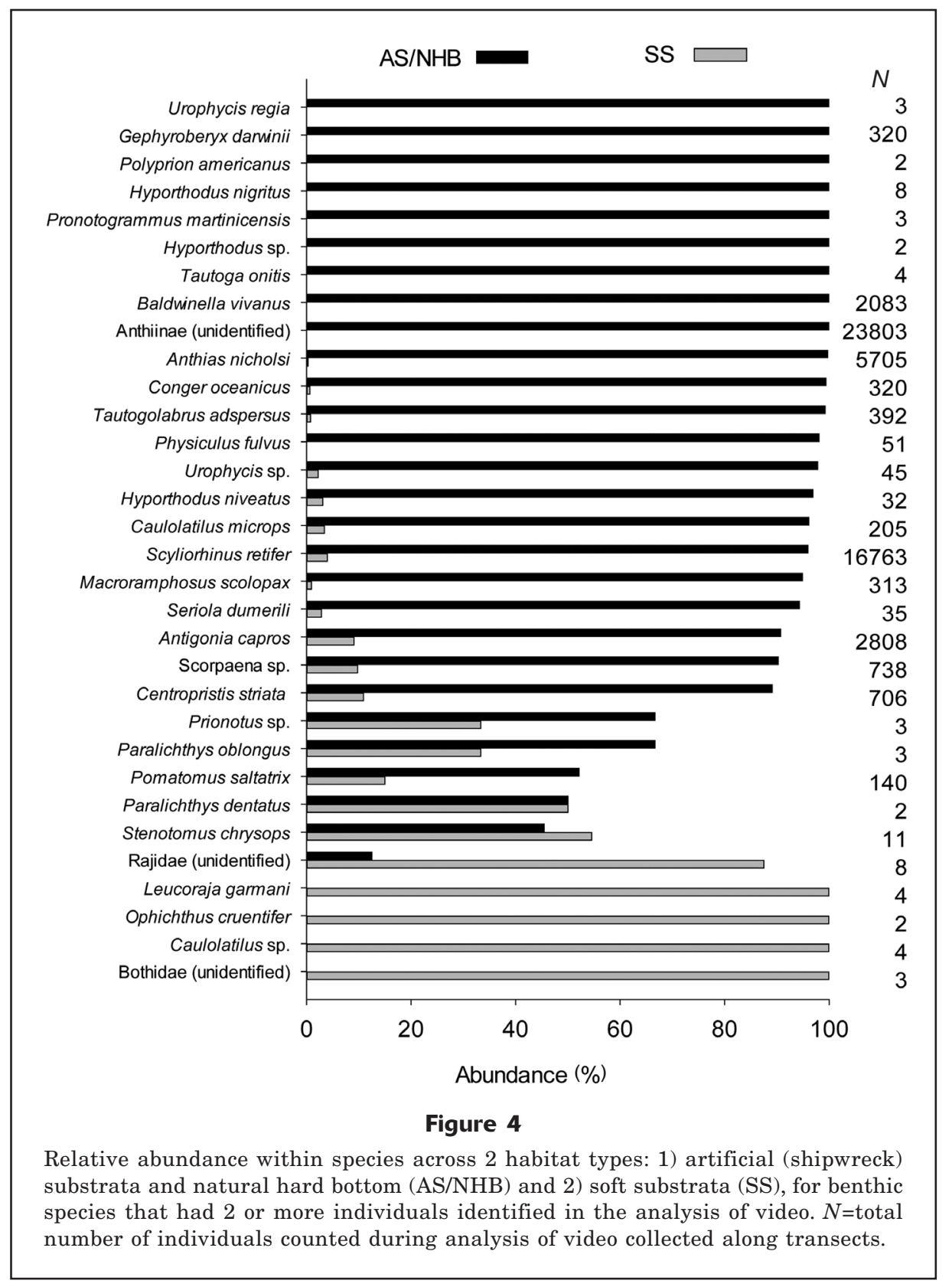

(e.g., goosefish [Lophius americanus], spotted hake [Urophycis regia], fourspot flounder, summer flounder). The most abundant taxa observed in our study (i.e., the chain dogfish, Anthiinae, and the deepbody boarfish), as well as others known to be reef associates (e.g., groupers, the blueline tilefish, and wrasses [Labridae]), were not abundant or were not reported in those earlier trawl-based studies (see also Grosslein and Azarovitz, 1982). The differences in species composition, largely resulting from sampling constraints imposed by trawls, emphasize the high degree of separation between fish communities on soft-bottom and those on reef-like habitats in the MAB.

Although Grimes et al. (1986) and Ross et al. (2015) conducted visual surveys that covered extensive complex habitats in the region, they reported only $2(25 \%$ overlap) and 10 (12\% overlap) fish species, respectively, in common with those observed in our study. In those 2 studies, the faunal differences can be attributed to deeper waters or a sampling areas much farther north than those surveyed in our study. Although also completed farther north $\left(\sim 41^{\circ} \mathrm{N}\right)$, visual surveys (Auster et al., 1995) conducted over flat, primarily sand and shell bottom (sites at depths of $55,240,712 \mathrm{~m}$ ) yielded $37.5 \%$ fish species in common with our study, and most of those species exhibited broad habitat affinity or affinity for soft bottom. In contrast, the MAB hard-bottom habitats surveyed in our study shared $43 \%$ of the fish 
fauna with a deep (depths of 237-253 m) shipwreck off Cape Fear, North Carolina, that was assessed during one earlier ROV dive (Quattrini and Ross, 2006). Many $(\sim 30 \%)$ of the reef-associated fishes reported here are common on outer shelf hard grounds throughout the southeastern United States (Grimes et al., 1982; Quattrini and Ross, 2006), also indicating a warm-temperate affinity for reef fishes of the southern MAB.

As with the reefs of the middle to outer shelf, hardbottom habitats of the shallower inner shelf of the MAB were dominated by relatively few, but different, fish species (i.e., the black sea bass, tautog, cunner, and scup). On the deeper hard-bottom habitats surveyed in this study, the black sea bass, tautog, and scup ranked below the top 6 species in abundance. Previous shelf studies were conducted in much shallower water (depths <35 m) (Briggs, 1975; Feigenbaum et al., 1985; Eklund and Targett, 1991; Adams, 1993), and not many small species were caught in 2 studies that relied heavily on data from fish traps. However, taxa like the Anthiinae, most common on deeper reefs (Anderson and Heemstra, 2012), are unlikely to occur on inshore reefs. Although regionally limited in general, hard-bottom habitats and associated data that can be recorded there are even more rare along the outer shelf (i.e., 100-m depth zone; Steimle and Zetlin, 2000). Despite the restricted scope of these deep shelf reefs, they support economically important fishes (e.g., groupers, tilefishes, and black sea bass) and exhibit a high species richness of fishes, as do reefs at similar depths south of Cape Hatteras (Parker and Ross, 1986; Quattrini and Ross, 2006).

A degree of faunal stability along the outer shelf of the southern MAB is indicated by similarities between years or seasons for the 4 study sites sampled in both seasons and both years. Although many fish species shift distributions by season in the MAB (Murawski et al., 1983), such movements may be less pronounced in deeper waters. A relatively small $\left(\sim 2^{\circ} \mathrm{C}\right)$ variation in bottom temperatures along the outer shelf (depth $\sim 100$ m) was correlated with consistent groupings of softbottom species across seasons and years (Colvocoresses and Musick, 1984). Grimes et al. (1986) noted that the region from southern New England to the MAB was often occupied by a warmer $\left(9-14^{\circ} \mathrm{C}\right)$ bottom water mass from depths of about $100-300 \mathrm{~m}$. In contrast, there were distinct seasonal differences in fish communities correlated with temperature, which varied over a range of $16.7^{\circ} \mathrm{C}$, on an artificial reef in much shallower water, at a depth of $21 \mathrm{~m}$, off Virginia (Adams, 1993). For the deeper shipwreck sites that we sampled during 2 seasons, only a mean bottom temperature difference $<1.5^{\circ} \mathrm{C}$ was observed between the 2 survey periods. Although more continuous and long-term environmental data are needed to capture more accurate means and especially variability, our results agree with the larger data set from Colvocoresses and Musick (1984).

Colton (1972) noted a series of warming and cooling trends on the shelf in the Gulf of Maine, but there was also little apparent change in the distributions of
4 groundfish species correlated with these temperature shifts. Because obligate reef fishes usually exhibit strong site or area fidelity, as long as bottom temperatures remain within tolerances, much of the reef fish community (e.g., Anthiinae and Hyporthodus spp.) on the outer shelf of the MAB should continue to occupy these hard-bottom sites. However, episodic intrusions of cold water from the north or from the deep sea can jeopardize some species of the reef fish community of the MAB outer shelf and could cause mass mortalities as documented for tilefish (Marsh et al., 1999).

As previously suggested (Murawski et al., 1983; Nye et al., 2009; Møller et al., 2010), it is tempting to propose that hard-bottom habitats of the southern MAB are increasingly invaded by more warm-temperate species, possibly in response to rising ocean temperatures. North Carolina is the closest southern source where many of the species noted here are abundant on extensive outer shelf hard-bottom habitats (Grimes et al., 1982; Parker and Mays, 1998; Quattrini and Ross, 2006). Although Cape Henry, Virginia, was listed with question as the northern limit of blueline tilefish (Dooley, 1978), our observations confirm its presence in the MAB (Fig. 2E) and extend its range north of Norfolk Canyon. That species, and the yellowfin bass, had been reported from this region from the early $20^{\text {th }}$ century (Firth, 1933, 1937). Snowy grouper (Hyporthodus niveatus) and warsaw grouper (H. nigritus) (Fig. 2, $\mathrm{C}$ and D) were reported in New England waters as early as the late $19^{\text {th }}$ century, but in most of these cases the fish were juveniles collected inshore and assumed to be strays (Smith, 1971). Large adults (documented in world tackle records) of snowy grouper recently occurred in the MAB recreational hook-and-line fishery (as did blueline tilefish), but data presented here are the first descriptions of their relative abundance and adult habitat along the outer shelf of the MAB. Recent collections of red barbier near Wilmington Canyon represent the first records of that species for the MAB (Moore et al., 2003), but this small, deep-reef-specific fish could have easily escaped detection. Similarly, our observations of 3 individuals of roughtongue bass (Pronotogrammus martinicensis) at depths of $92 \mathrm{~m}$ on the natural hard bottom represent a new northern range limit (from North Carolina, Anderson and Heemstra, 2012) for this species, but this observation does not necessarily mean that this species is newly arrived to the MAB. Although historical data have been inadequate (because of a lack of appropriate sampling on deep reefs) to allow an evaluation of long-term changes in the patterns of hard-bottom species composition on the MAB outer shelf, this study, the first to examine outer shelf reef fishes of this region, should provide a baseline for future assessments.

\section{Acknowledgments}

Funding for this project was supplied by the Bureau of Ocean Energy Management (BOEM) (contracted to CSA 
Ocean Sciences Inc.). We thank G. Boland (BOEM) for support during the development of the overall project. The NOAA Ships Nancy Foster and Ronald H. Brown and the Kraken II and Jason II ROVs were provided by the NOAA Office of Ocean Exploration and Research. S. Brooke (Florida State University) assisted with all aspects of organizing and managing the project and cruises. T. Munroe assisted with identifications of flatfishes. A. Quattrini assisted with some statistical analysis. We thank the ship and shore-based personnel who operated the ships and ROVs, and all the science and outreach personnel for their hard work during the cruises.

\section{Literature cited}

Able, K. W., and D. Flescher.

1991. Distribution and habitat of chain dogfish, Scyliorhinus retifer, in the Mid-Atlantic Bight. Copeia 1991:231-234. Article

Able, K. W., and M. P. Fahay.

1998. First year in the life of estuarine fishes in the Middle Atlantic Bight, 342 p. Rutgers Univ. Press, New Brunswick, NJ.

Adams, A. J.

1993. Dynamics of fish assemblages associated with an offshore artificial reef in the southern Mid-Atlantic Bight. M.A. thesis, 97 p. College of William and Mary, Williamsburg, VA.

Anderson, M. J., R. N. Gorley, and K. R. Clarke.

2008. PERMANOVA+ for PRIMER: guide to software and statistical methods, 214 p. PRIMER-E, Plymouth, U.K.

Anderson, W. D., Jr., and P. C. Heemstra.

2012. Review of Atlantic and eastern Pacific anthiine fishes (Teleostei: Perciformes: Serranidae), with descriptions of two new genera. Transactions, vol. 102, pt. 2, 192 p. Am. Philos. Soc., Philadelphia, PA.

Arena, P. T., L. K. B. Jordan, and R. E. Spieler.

2007. Fish assemblages on sunken vessels and natural reefs in southeast Florida, USA. Hydrobiologia 580:157-171. Article

Auster, P. J., R. J. Malatesta, and S. C. LaRosa, R. A. Cooper, and L. L. Stewart.

1991. Micro habitat utilization by the megafaunal assemblage at a low relief outer continental shelf siteMiddle Atlantic Bight, USA. J. Northwest Atl. Fish. Sci. 11:59-69.

Auster, P. J., R. J. Malatesta, and S. C. LaRosa.

1995. Patterns of microhabitat utilization by mobile megafauna on the southern New England (USA) continental shelf and slope. Mar. Ecol. Prog. Ser. 127:77-85. Article

Briggs, P. T.

1975. An evaluation of artificial reefs in New York's marine waters. N.Y. Fish Game J. 22:51-56.

Cailliet, G. M., A. H. Andrews, W. W. Wakefield, G. Moreno, and K. L. Rhodes.

1999. Fish faunal and habitat analyses using trawls, camera sleds and submersibles in benthic deep-sea habitats off central California. Oceanologica Acta 22:579-592. Article

Clarke, K. R., and R. M. Warwick.

2001. Change in marine communities: an approach to statistical analysis and interpretation, $2^{\text {nd }}$ ed, $172 \mathrm{p}$. PRIMER-E, Plymouth, U.K.
Clarke, K. R., and R.N., Gorley.

2006. PRIMER v6: user manual/tutorial, 192 p. PRIMER-E, Plymouth, U.K.

Colton, J. B., Jr.

1972. Temperature trends and the distribution of groundfish in continental shelf waters, Nova Scotia to Long Island. Fish. Bull. 70:637-657.

Colvocoresses, J. A., and J. A. Musick.

1984. Species associations and community composition of Middle Atlantic Bight continental shelf demersal fishes. Fish. Bull. 82:295-313.

Craig, M. T., Y. J. Sadovy de Mitcheson, and P. C. Heemstra. 2011. Groupers of the world: a field and market guide, $356 \mathrm{p}$. NISC Ltd., Grahamstown, South Africa.

Diaz, R. J., G. R. Cutter Jr., and K. W. Able.

2003. The importance of physical and biogenic structure to juvenile fishes on the shallow inner continental shelf. Estuaries 26:12-20. Article

Dooley, J. K.

1978. Systematics and biology of the tilefishes (Perciformes: Branchiostegidae and Malacanthidae), with descriptions of two new species. NOAA Tech. Rep. NMFS Circ. 411,78 p.

Eklund, A-M.

1988. Fishes inhabiting hard bottom reef areas in the Middle Atlantic Bight: seasonality of species composition, catch rates and reproduction. M.S. thesis, 98 p. Univ. Delaware, Newark, DE.

Eklund, A-M., and T. E. Targett.

1991. Seasonality of fish catch rates and species composition from the hard bottom trap fishery in the Middle Atlantic Bight (US east coast). Fish. Res. 12:1-22. Article

Feigenbaum, D., C. H. Blair, M. Bell, J. R. Martin, and M. G. Kelly.

1985. Virginia's artificial reef study: description and results of year 1. Bull. Mar. Sci. 37:179-188.

Firth, F. E.

1933. Anthias nicholsi, a new fish taken off Virginia in the deep-water trawl fishery. Copeia 1933:158-160. Article

1937. Recent records extending the range of Caulolatilus microps north of Florida. Copeia 1937:189. Article

Gabriel, W. L.

1992. Persistence of demersal fish assemblages between Cape Hatteras and Nova Scotia, northwest Atlantic. J. Northwest Atl. Fish. Sci. 14:29-46.

Grimes, C. B., C. S. Manooch, and G. R. Huntsman.

1982. Reef and rock outcropping fishes of the outer continental shelf of North Carolina and South Carolina, and ecological notes on the red porgy and vermilion snapper. Bull. Mar. Sci. 32:277-289.

Grimes, C. B., K. W. Able, and R. S. Jones.

1986. Tilefish, Lopholatilus chamaeleonticeps, habitat, behavior and community structure in Mid-Atlantic and southern New England waters. Environ. Biol. Fishes 15:273-292.

Grosslein, M. D., and T. R. Azarovitz.

1982. Fish Distribution. MESA New York Bight Atlas Monograph 15, 182 p. NY Sea Grant Inst. Albany, NY.

Grossman, G. D., G. P. Jones, and W. J. Seaman Jr.

1997. Do artificial reefs increase regional fish production? A review of existing data. Fisheries 22:17-23. Article

Lee, J.

1949. The bombs heard round the world. Flying 45:2425,68 . 
Mahon, R., S. K. Brown, K. C. T. Zwanenburg, D. B. Atkinson, K. R. Buja, L. Claflin, G. D. Howell, M. E. Monaco, R. N. O'Boyle, and M. Sinclair.

1998. Assemblages and biogeography of demersal fishes of the east coast of North America. Can. J. Fish. Aquat. Sci. 55:1704-1738. Article

Marsh, R., B. Petrie, C. R. Weidman, R. R. Dickson, J. W. Loder, C. G. Hannah, K. Frank, and K. Drinkwater.

1999. The 1882 tilefish kill—a cold event in shelf waters off the north-eastern United States? Fish. Oceanogr. 8:39-49. Article

Møller, P. R., J. G. Nielsen, S. W. Knudsen, J. Y. Poulsen, K. Sünksen, and O. A. Jørgensen.

2010. A checklist of the fish fauna of Greenland waters. Zootaxa 2378:1-84.

Moore, J. A., K. E. Hartel, J. E. Craddock, and J. K. Galbraith, 2003. An annotated list of deepwater fishes from off the New England region, with new area records. Northeast. Nat. 10:159-248. Article

Murdy, E. O., R. S. Birdsong, and J. A. Musick.

1997. Fishes of Chesapeake Bay, 324 p. Smithsonian Inst. Press, Washington, DC.

Murawski, S. A., A. M. Lange, M. P. Sissenwine, and R. K. Mayo.

1983. Definition and analysis of multispecies otter-trawl fisheries off the northeast coast of the United States. J. Cons. Int. Explor. Mer 41:13-27. Article

Nye, J. A., J. S. Link, J. A. Hare, and W. J. Overholtz, 2009. Changing spatial distribution of fish stocks in relation to climate and population size on the Northeast United States continental shelf. Mar. Ecol. Prog. Ser. 393:111-129. Article

Parker, R. O., Jr., and S. W. Ross.

1986. Observing reef fishes from submersibles off North Carolina. Northeast Gulf Sci. 8:31-49.

Parker, R. O., Jr., and R. W. Mays.

1998. Southeastern U.S. deepwater reef fish assemblages, habitat characteristics, catches, and life history summaries. NOAA Tech. Rep. NMFS 138, 41 p.
Perkol-Finkel, S., N. Shashar, and Y. Benayahu.

2006. Can artificial reefs mimic natural reef communities?

The roles of structural features and age. Mar. Environ. Res. 61:121-135. Article

Quattrini, A. M., and S. W. Ross.

2006. Fishes associated with North Carolina shelf-edge hardbottoms and initial assessment of a proposed marine protected area. Bull. Mar. Sci. 79:137-163.

Quattrini, A. M, S. W. Ross, M. C. T. Carlson, and M.S. Nizinski.

2012. Megafaunal-habitat associations at a deep-sea coral mound off North Carolina, USA. Mar. Biol. 159:1079-1094. Article

Ross, S. W., and A. M., Quattrini.

2007. The fish fauna associated with deep coral banks off the southeastern United States. Deep-Sea Res. (I Oceanogr. Res. Pap.) 54:975-1007. Article

Ross, S. W., M. Rhode, and A. M. Quattrini.

2015. Demersal fish distribution and habitat use within and near Baltimore and Norfolk canyons, U.S. middle Atlantic slope. Deep-Sea Res. (I. Oceanogr. Res. Pap.) 103:137-154. Article

SEAMAP-SA (Southeast Area Monitoring and Assessment Program-South Atlantic).

2001. Distribution of bottom habitats on the continental shelf from North Carolina through the Florida Keys, $166 \mathrm{p}$. SEAMAP-SA Bottom Mapping Workgroup, Atlantic States Marine Fisheries Commission, Washington, D.C.

Smith, C. L.

1971. A revision of the American groupers: Epinephelus and allied genera. Bull. Am. Mus. Nat. Hist. 146:67-242.

Steimle, F. W., and C. Zetlin.

2000. Reef habitats in the Middle Atlantic Bight: abundance, distribution, associated biological communities, and fishery resource use. Mar. Fish. Rev. 62(2):24-42.

Stephan, D. C., and D. G. Lindquist.

1989. A comparative analysis of the fish assemblages associated with old and new shipwrecks and fish aggregating devices in Onslow Bay, North Carolina. Bull. Mar. Sci. 44:698-717. 